\title{
The transcription factor GATA6 is essential for branching morphogenesis and epithelial cell differentiation during fetal pulmonary development
}

\author{
Richard Keijzer ${ }^{1,2, \ddagger}$, Minke van Tuyl ${ }^{2,3}$, Carel Meijers ${ }^{1,2}$, Martin Post $^{3}$, Dick Tibboel ${ }^{2}$, Frank Grosveld ${ }^{1, \star}$ and \\ Manoussos Koutsourakis ${ }^{1, \neq}$ \\ ${ }^{1}$ Department of Cell Biology and Genetics, Erasmus University Medical Centre Rotterdam, Rotterdam, The Netherlands \\ 2Department of Pediatric Surgery, Sophia Children's Hospital, Erasmus University Medical Centre Rotterdam, Rotterdam, The \\ Netherlands \\ 3Lung Biology Research Program, Hospital for Sick Children Research Institute, Department of Pediatrics, University of Toronto, \\ Toronto, Ontario, Canada \\ *Author for correspondence (e-mail: grosveld@ch1.fgg.eur.nl) \\ ‡Both authors contributed equally to this work \\ Accepted 6 December 2000; published on WWW 23 January 2001
}

\section{SUMMARY}

Recent loss-of-function studies in mice show that the transcription factor GATA6 is important for visceral endoderm differentiation. It is also expressed in early bronchial epithelium and the observation that this tissue does not receive any contribution from Gata6 double mutant embryonic stem (ES) cells in chimeric mice suggests that GATA6 may play a crucial role in lung development. The aim of this study was to determine the role of GATA6 in fetal pulmonary development. We show that Gata6 mRNA is expressed predominantly in the developing pulmonary endoderm and epithelium, but at E15.5 also in the pulmonary mesenchyme. Blocking or depleting GATA6 function results in diminished branching morphogenesis both in vitro and in vivo. TTF1 expression is unaltered in chimeric lungs whereas SPC and CC10 expression are attenuated in abnormally branched areas of chimeric lungs. Chimeras generated in a ROSA26 background show that endodermal cells in these abnormally branched areas are derived from Gata6 mutant ES cells, implicating that the defect is intrinsic to the endoderm. Taken together, these data demonstrate that GATA6 is not essential for endoderm specification, but is required for normal branching morphogenesis and late epithelial cell differentiation.

Key words: GATA6, Branching morphogenesis, Lung, Endoderm differentiation, Mouse

\section{INTRODUCTION}

The formation of a lung requires a well organized program to coordinate the balanced interplay between activation and repression of gene transcription as it develops from a cluster of cells in the floor of the primitive foregut to the highly vascularized gas exchange organ (Hogan, 1999; Warburton et al., 2000). Several evolutionarily conserved signaling pathways have been implicated in the different stages of fetal pulmonary development. In particular members of the fibroblast growth factor, bone morphogenetic protein, hedgehog/Gli, wingless and epidermal growth factor families have been demonstrated to be key regulatory factors for lung morphogenesis and epithelial differentiation, but lung endoderm specification is less well understood (for reviews see Hogan, 1999; Warburton et al., 2000). Recently, a member of the GATA family of transcription factors, GATA6, has been implicated in endoderm specification (Morrisey et al., 1998). In vertebrates, the GATA family of transcription factors contains a conserved zinc-finger motif that binds to the consensus sequence A/TGATA/G resulting in transcriptional regulation of genes in different cell lineages (for reviews see Charron and Nemer, 1999; Evans, 1997; Jordan and Van Zant, 1998; Orkin, 2000). The GATA transcription factors can be subdivided into two main groups. First, GATA1, GATA2 and GATA3, which all have unique functions in the hematopoietic system (Leonard et al., 1993; Pandolfi et al., 1995; Pevny et al., 1991; Simon et al., 1992; Ting et al., 1996; Tsai et al., 1994; Weiss et al., 1994; Whyatt et al., 2000) and, in case of GATA2 and GATA3, in many other tissues, including the nervous system and the kidneys. Second, GATA4, GATA5 and GATA6, which are mainly expressed and involved in the formation of the extra-embryonic and embryonic endoderm, as well as in the cardiogenic mesoderm (Arceci et al., 1993; Koutsourakis et al., 1999; Laverriere et al., 1994; Morrisey et al., 1996; Morrisey et al., 1997a; Morrisey et al., 1997b; Morrisey et al., 1998).

Radioactive in situ hybridization experiments have demonstrated that GATA6 mRNA is expressed in the developing embryonic bronchial epithelium and in chimeric experiments this endodermally derived tissue did not receive any contribution from Gata6 $^{-l-}$ ES cells (Morrisey et al., 1996; Morrisey et al., 1998). The conclusion of these studies was that 
GATA6 is required for specification of lung endoderm. In addition, the promoters of several lung specific genes, such as the genes for human thyroid transcription factor 1 , human surfactant protein $\mathrm{C}$, mouse surfactant protein A and mouse Clara cell marker 10, contain GATA motifs (Ikeda et al., 1995; Korfhagen et al., 1992; Ray et al., 1993; Wert et al., 1993) and GATA6 has also been shown to activate both surfactant protein A and thyroid transcription factor 1 reporter gene transcription in vitro (Bruno et al., 2000; Shaw-White et al., 1999). Taken together, these data strongly suggest that GATA6 plays an important role during lung development.

We therefore searched to identify the specific role(s) of GATA6 in fetal pulmonary development. In order to obtain a more detailed insight into the spatial-temporal distribution of GATA6 mRNA, non-radioactive in situ hybridization during fetal lung development in vivo was performed. The observed expression patterns in early embryonic lungs suggest a role for GATA6 in branching morphogenesis, which we investigated using organotypic explant cultures with antisense oligonucleotides. To confirm and further investigate the role of GATA6 in lung development in vivo, we also generated highly chimeric embryos by injecting wild-type blastocysts with Gata6 $^{-1-}$ embryonic stem (ES) cells. The latter experiments enabled us to overcome the early embryonic lethality in Gata6 $^{-1-}$ mice, which is due to extra-embryonic defects (Koutsourakis et al., 1999; Morrisey et al., 1998), because in such chimeras, the extra-embryonic tissues are provided by the wild-type host blastocyst. Highly chimeric lungs were histologically analyzed and the expression of molecular markers for endoderm specification and epithelial cell differentiation (thyroid transcription factor 1, surfactant protein $\mathrm{C}$ and Clara cell marker 10) was investigated using immunohistochemistry and in situ hybridization.

Branching morphogenesis was dramatically affected in vitro when antisense oligonucleotides for Gata6 were added to lung cultures. In chimeric embryos, pulmonary endoderm was formed but it branched abnormally and failed to undergo late epithelial cell differentiation, based on diminished surfactant protein C (SPC; Sftpc - Mouse Genome Informatics) and Clara cell marker 10 (CC10; Utg - Mouse Genome Informatics) expression. Using ROSA26 recipient blastocysts, we demonstrate that this abnormal epithelium is derived from Gata6 $^{-1-}$ ES cells. We conclude that GATA6 is essential for the later stages of branching morphogenesis and late epithelial cell differentiation, but not for lung endoderm specification.

\section{MATERIALS AND METHODS}

\section{Whole-mount in situ hybridization}

Wild type embryonic day (E) 10.5 and E12.5 embryos were isolated from pregnant FVB female mice according to standard methods (Hogan et al., 1994) and the lungs were dissected from these embryos using microsurgical techniques. The lungs were fixed in $4 \%(\mathrm{w} / \mathrm{v})$ paraformaldehyde in phosphate-buffered saline (PBS) at $4^{\circ} \mathrm{C}$ for 4 to 6 hours, dehydrated in a graded series of ethanol and kept in 100\% methanol at $-20^{\circ} \mathrm{C}$ until used. The whole-mount in situ hybridization protocol was adapted from the protocol described by Wilkinson (Wilkinson, 1993). In short, following hydration, the lungs were bleached for 1 hour in $6 \%(\mathrm{v} / \mathrm{v})$ hydrogen peroxide in PBS containing $0.1 \%(\mathrm{v} / \mathrm{v})$ Tween-20 (PBT) and permeabilized with proteinase K (10 $\mu \mathrm{g} . \mathrm{ml}^{-1}$ in PBT) for 15 minutes at room temperature. Subsequently, the lungs were post-fixed in $4 \%(\mathrm{w} / \mathrm{v})$ paraformaldehyde in PBS and prehybridized in hybridization mixture, containing $50 \%$ formamide, $5 \times \mathrm{SSC}(\mathrm{NaCl} 0.75 \mathrm{~mol} / \mathrm{l}$, sodium citrate $0.075 \mathrm{~mol} / \mathrm{l}, \mathrm{pH} 4.5), 1 \%$ sodium dodecyl sulphate, $5 \mu \mathrm{g} . \mathrm{ml}^{-1}$ yeast tRNA, $50 \mu \mathrm{g} . \mathrm{ml}^{-1}$ heparin in water for 1 hour at $70^{\circ} \mathrm{C}$. Hybridization was carried out for 16 to 18 hours at $70^{\circ} \mathrm{C}$ using the same hybridization mixture, but now containing a digoxigenin (DIG)-labeled sense or antisense GATA6 RNA probe. A $1.5 \mathrm{~kb}$ fragment of the $5^{\prime}$ end of the mouse Gata6 gene that was described previously (Brewer et al., 1999) was used to generate a probe for in situ hybridization on sections. A Pst $\mathrm{I}-N o t \mathrm{I}$ subclone from the $5^{\prime}$ part of this $1.5 \mathrm{~kb}$ fragment was used to generate a probe for whole-mount in situ hybridization. The cDNA fragments were DIG-labeled according to a protocol provided by the manufacturer (Roche Diagnostics, Almere, The Netherlands). The next day, the lungs were stringently washed and treated with RNAse to avoid nonspecific background staining. Following a blocking step using $10 \%$ (v/v) sheep serum in $0.14 \mathrm{~mol} / \mathrm{l} \mathrm{NaCl}, 2.7 \mathrm{mmol} / \mathrm{l} \mathrm{KCl}, 25$ $\mathrm{mmol} / \mathrm{l} \mathrm{Tris} / \mathrm{HCl} \mathrm{pH} 7.5$ and $0.1 \%(\mathrm{v} / \mathrm{v})$ Tween-20 in water (TBST) including $2 \mathrm{mmol} / \mathrm{l}$ levamisole, the lungs were incubated with an alkaline phosphatase-coupled antibody (1:2000), against DIG for 16 to 18 hours at $4^{\circ} \mathrm{C}$. For at least 3 days the lungs were then washed in TBST and $2 \mathrm{mmol} / \mathrm{l}$ levamisole. The lungs were changed to $0.1 \mathrm{~mol} / \mathrm{l}$ $\mathrm{NaCl}, 0.1 \mathrm{~mol} / \mathrm{l}$ Tris$/ \mathrm{HCl}, \mathrm{pH} 9.5,0.05 \mathrm{~mol} / \mathrm{l} \mathrm{MgCl}_{2}$ and $0.1 \%(\mathrm{v} / \mathrm{v})$ Tween-20 (NTMT) and the hybridized probe was visualized using $337.5 \mu \mathrm{g} \cdot \mathrm{ml}^{-1} \mathrm{NBT}$ and $175 \mu \mathrm{g} \cdot \mathrm{ml}^{-1}$ BCIP mixture as a substrate. Nonspecific labeling was removed in $95 \%$ ethanol, and the lungs were kept at $4^{\circ} \mathrm{C}$ in PBT containing $1 \mathrm{mmol} / \mathrm{l}$ EDTA.

\section{Branching morphogenesis in vitro with antisense oligonucleotides}

E11.5 and E12.5 lungs were harvested from wild-type embryos under a dissection microscope. The lungs were transferred to porous membranes ( $8 \mu \mathrm{m}$ pore size) from Nucleopore (Whatman, NY), and incubated in 12-well culture plates from Costar (Corning, NY). The membranes were pre-soaked in MEM (Gibco) for 1 hour before the explants were placed on them. The explants were incubated as floating cultures in $500 \mu \mathrm{l}$ Dulbecco's modified Eagle's medium, nutrient mixture F-12 (Gibco) supplemented with $100 \mu \mathrm{g} / \mathrm{ml}$ streptomycin, 100 units $/ \mathrm{ml}$ penicillin and $0.25 \mathrm{mg} / \mathrm{ml}$ ascorbic acid. The explants were cultured at $37^{\circ} \mathrm{C}$ in $95 \%$ air and $5 \% \mathrm{CO}_{2}$. Ten cultured lungs were treated with $40 \mu \mathrm{M}$ phosphorothioated oligonucleotides, targeted against the translation initiation site of the murine Gata6 mRNA in the antisense direction with the following sequence: GTCAGTCAAGGCCAT. Ten cultured lungs were treated with the same concentration sense-orientated oligonucleotides with the following sequence: ATGGCCTTGACTGAC. Ten untreated cultured lungs served as controls. The lungs were cultured for up to 72 hours and branching morphogenesis was monitored daily and images captured using a dissecting microscope (Leica MZ12) and the Leica Digital Imaging Systems.

\section{Generation of chimeric embryos}

In contrast to standard procedures, we injected more than $20 \mathrm{Gata}^{-/-}$, or $\mathrm{Gata6}^{+-}$for the control experiment, ES cells into each blastocyst in order to obtain highly chimeric embryos. These injections were performed either in C57BL/6 or ROSA26 (Friedrich and Soriano, 1991) blastocysts and the ES cell lines used have been previously described (Koutsourakis et al., 1999). Chimeric lungs were dissected at E12.5, E13.5, E15.5 or E18.5 and either processed for explant cultures (E13.5), as described above, or fixed and used for histological analysis and in situ hybridization, as described above (E12.5, E15.5 and E18.5). Head or tail tissue of the embryos was used to determine the percentage of chimerism using Glucose Phosphate Isomerase (GPI) electrophoresis (Hogan et al., 1994).

\section{In situ hybridization and immunohistochemistry}

Non-radioactive in situ hybridization on $6 \mu \mathrm{m}$ sections with SPC and 
CC10 RNA probes was carried out essentially as described before by Motoyama et al. (Motoyama et al., 1998). In short, tissue sections were rehydrated and washed in PBS. Pretreatment included postfixation in $4 \%$ paraformaldehyde for 15 minutes, followed by proteinase $\mathrm{K}$ digestion $(20 \mathrm{mg} / \mathrm{ml})$ for 15 minutes at room temperature and acetylation $(0.1 \mathrm{~mol} / \mathrm{l}$ triethanolamine and $0.25 \%$ acetic anhydride) for 10 minutes at room temperature. Sections were then dehydrated and air-dried before addition of the hybridization solution. Digoxigenin-labeled probes were added to freshly prepared hybridization solution $(50 \%$ deionized formamide, $10 \%$ dextran sulfate, $1.5 \times$ Denhardt's reagent, $0.5 \mathrm{mg} / \mathrm{ml}$ of yeast tRNA, $0.3 \mathrm{~mol} / \mathrm{l}$ $\mathrm{NaCl}, 5 \mathrm{mmol} / \mathrm{l}$ EDTA and $25 \mathrm{mmol} / \mathrm{l}$ Tris, $\mathrm{pH}$ 7.5) at a concentration of $1 \mathrm{ng} / \mu \mathrm{l}$. Following denaturation at $80^{\circ} \mathrm{C}$, the probe was added to the tissue section and incubated for 16 to 18 hours at $55^{\circ} \mathrm{C}$. After brief washes with $5 \times \mathrm{SSC}$ and $50 \%$ formamide at $55^{\circ} \mathrm{C}$, the tissue was treated with RNase A $(10 \mu \mathrm{g} / \mathrm{ml})$ for 30 minutes at $37^{\circ} \mathrm{C}$. The digoxigenin nucleic acid detection kit (Roche Diagnostics, Almere, The Netherlands) was used for immunological detection of the hybridized probe. Tissue was then counterstained with Methyl Green and prepared for viewing.

Mouse specific SPC and CC10 cDNA fragments (330 and 315 bases, respectively) were DIG labeled according to a protocol provided by the manufacturer (Roche Diagnostics, Almere, The Netherlands). Immunohistochemistry with a monoclonal antibody against thyroid transcription factor 1 (TTF1) (Neomarkers, CA, USA) in a concentration of 1 in 100 was carried out as described before (Keijzer et al., 2000).

\section{RESULTS}

\section{Spatial-temporal expression of Gata6 mRNA during fetal lung development}

Starting from E10.5, when five primary lung buds have just evaginated from the foregut, Gata6 mRNA was detected in developing lung endoderm (Fig. 1A). At this stage, the Gata6 mRNA was predominantly expressed at the tips of the growing lung buds. Two days later at E12.5, when branching morphogenesis of the lung buds is proceeding rapidly in order to establish the future bronchial tree, Gata6 mRNA was still observed in the branching endoderm. However, at this stage the signal was observed in the entire endoderm lining the developing lung buds, instead of being limited only to the tips of the growing buds (Fig. 1B). On sections of wild-type E15.5 lungs, in which branching morphogenesis is almost completed, and differentiation and vascularization are beginning, Gata6 mRNA was expressed in the endoderm lining the growing airways, as well as in parts of the mesenchyme surrounding these airways, albeit at a lower level (Fig. 1C). At E18.5, when the bronchial tree is complete, and the lung tissues are differentiating into the different cell types that will constitute the lung after birth, Gata6 mRNA was observed mainly in epithelial cells lining the bronchioli, but also to a lesser extent in the epithelial cells lining the sacculi (Fig. 1D). At this stage, the signal in the mesenchyme was difficult to distinguish, possibly because of the thinning of this tissue layer. Hybridization with sense RNA GATA6 probes generated no specific signal in either whole-mount or section in situ hybridization experiments at all stages (results not shown).

\section{Antisense oligonucleotides against Gata6 reduce branching morphogenesis in vitro}

Based on the mRNA expression pattern of Gata6, in particular expression in the endoderm lining the early lung buds, an important role for GATA6 in branching morphogenesis was anticipated. Antisense oligonucleotides targeted against the translation initiation site of Gata6 were used in explant cultures of isolated fetal lungs to investigate this role. When E11.5 lungs were cultured for 72 hours in the presence of antisense GATA6 oligonucleotides (Fig. 2B), branching morphogenesis of these lungs was clearly reduced when compared with the patterns of branching morphogenesis of lungs exposed to sense GATA6 oligonucleotides (Fig. 2A) or to lungs cultured in medium alone without oligonucleotides (not shown). A similar reduction in branching morphogenesis was observed when E12.5 lungs were cultured for 72 hours with antisense (Fig. 2D) oligonucleotides. Again, lungs exposed to sense oligonucleotides (Fig. 2C) and control lungs (not shown), which were cultured without oligonucleotides, demonstrated similar patterns of normal branching morphogenesis.

\section{Gata6 $^{-/-}$chimeric lungs display diminished branching morphogenesis in vitro}

In all experiments highly chimeric (more than 50\%) embryos and lungs were selected based on GPI analysis (results not shown). Isolated E12.5 Gata $^{-/-}$chimeric lungs were smaller in size and had less lung buds (Fig. 3B) when compared with non-chimeric littermates (Fig. 3A). From a different litter, E13.5 $\mathrm{Gata}^{-/-}$chimeric and non-chimeric lungs were cultured for 4 days as organotypic explants. At the time of isolation, both lungs were comparable in size, but the $\mathrm{Gata}^{-/-}$chimeric lungs had fewer branches (Fig. 3D) than the non-chimeric lungs (Fig. 3C). After 4 days of culture, the Gata6 $^{-1-}$ chimeric lungs demonstrated diminished branching morphogenesis in certain areas of the lung (Fig. 3F, arrow), whereas in other areas, branching morphogenesis patterns were the same as wild type (Fig. 3E).

\section{Gata6 $6^{-1-}$ chimeric lungs display diminished branching morphogenesis in vivo resulting in respiratory insufficiency}

When Gata6 $^{-1-}$ chimeric lungs were isolated at E15.5 they appeared similar to lungs isolated from non-chimeric littermates. The size was comparable, the lungs had four lobes on the right, one lobe on the left and no defect in branching morphogenesis was observed macroscopically (Fig. 4A,B). However, when these lungs were analyzed microscopically, a clear defect in branching morphogenesis indicated by the large airspaces was observed in the Gata6 $^{-1-}$ chimeric lungs (Fig. 4D, arrow), when compared with non-chimeric lungs (Fig. 4C). When chimeras were generated with the parental heterozygous ES cells, which were used to generate the double mutant lines (Koutsourakis et al., 1999), no abnormalities were observed in highly chimeric E15.5 lungs (results not shown). Chimeric E18.5 lungs, generated with Gata6 $^{-1-}$ ES cells (Fig. 4F) were again the same size as the non-chimeric lungs (Fig. 4E) from their littermates. In addition, chimeric lungs had four lobes on the right and one lobe on the left. However, at this stage a clear defect in branching morphogenesis was observed macroscopically in some Gata6 $^{-1-}$ chimeric lungs (Fig. 4F, arrows). This defect in branching morphogenesis was confirmed at the microscopic level (Fig. 4H).

Eight pups were delivered by Caesarian section at E18.5 following blastocyst injection. Without knowing their 

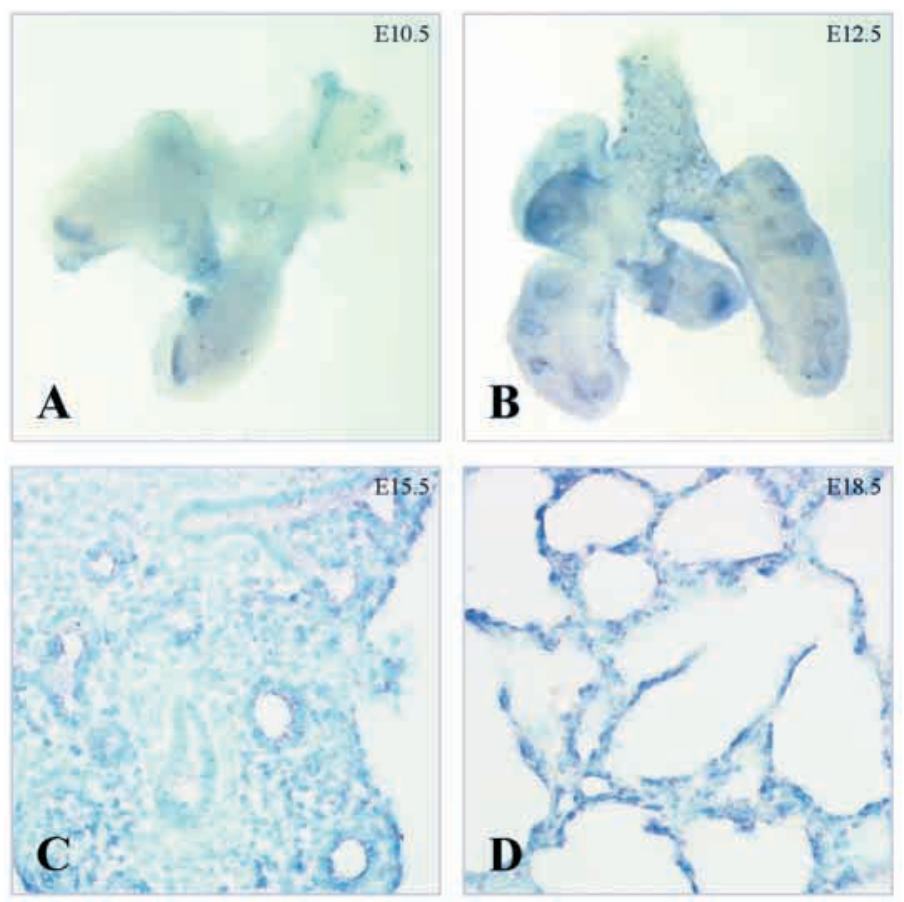

Fig. 1. Spatial-temporal distribution of Gata6 mRNA during embryonic and fetal pulmonary development. (A) At E10.5, Gata6 mRNA is predominantly expressed at the tips of the primary lung buds. (B) Two days later at E12.5, Gata6 mRNA expression has expanded and is now expressed in the entire endoderm lining the actively branching lung buds. (C) When branching morphogenesis is almost completed at E15.5, Gata6 mRNA is observed in the endoderm lining the growing airways, and in particular in the distal endoderm. In the mesenchyme, Gata6 mRNA is also observed, but at a lower level. (D) Finally, during maturation and differentiation at E18.5, Gata6 mRNA is expressed in epithelial cells lining the sacculi.
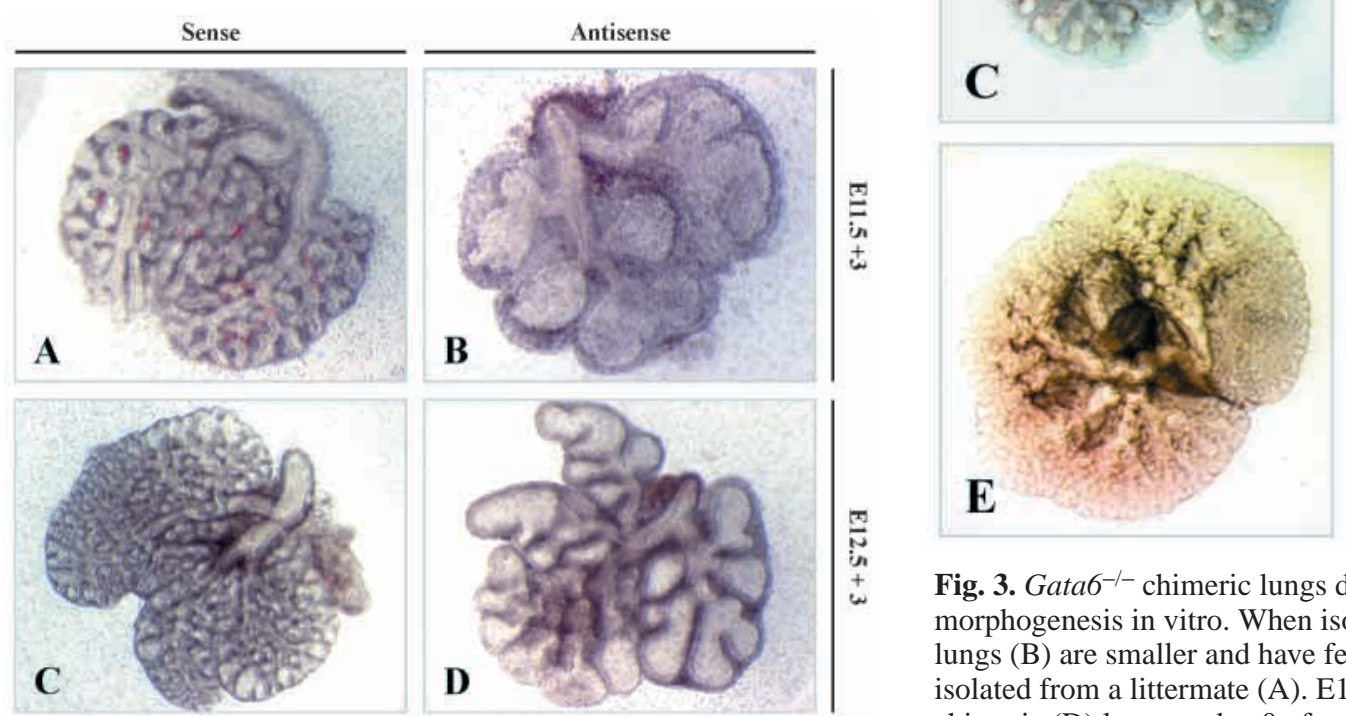

\section{B}

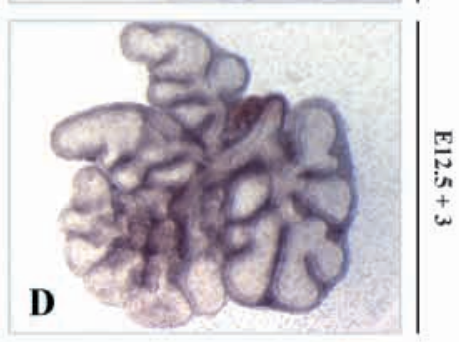

Fig. 2. GATA6 antisense oligonucleotides inhibit branching morphogenesis in vitro. Representative pictures of experiments with E11.5 (A,B) or E12.5 (C,D) wild-type lungs, cultured as organotypic explants in the presence of sense $(A, C)$ or antisense $(B, D)$ oligonucleotides targeted against the translation initiation site of Gata6. All pictures were taken at the same magnification. chimerism, the pups were stimulated to breathe. Out of the eight pups, two were mummified and three were born dead. Out of the three pups that were born alive, two appeared purplish-blue and one was pink. All three breathed normally. GPI electrophoresis demonstrated that only the pink pup was non-chimeric, and all other seven pups were highly chimeric (results not shown).

\section{Expression of SPC, CC10 and TTF1 in $\mathrm{Gata6}^{-/-}$ chimeric lungs}

In order to investigate if cell differentiation was altered in Gata6 $^{-/-}$chimeric lungs, non-radioactive in situ hybridization with probes for SPC, a marker for type II cells that indicates distal epithelial cell differentiation, and $\mathrm{CC} 10$, a marker for Clara cells that indicates proximal epithelial cell
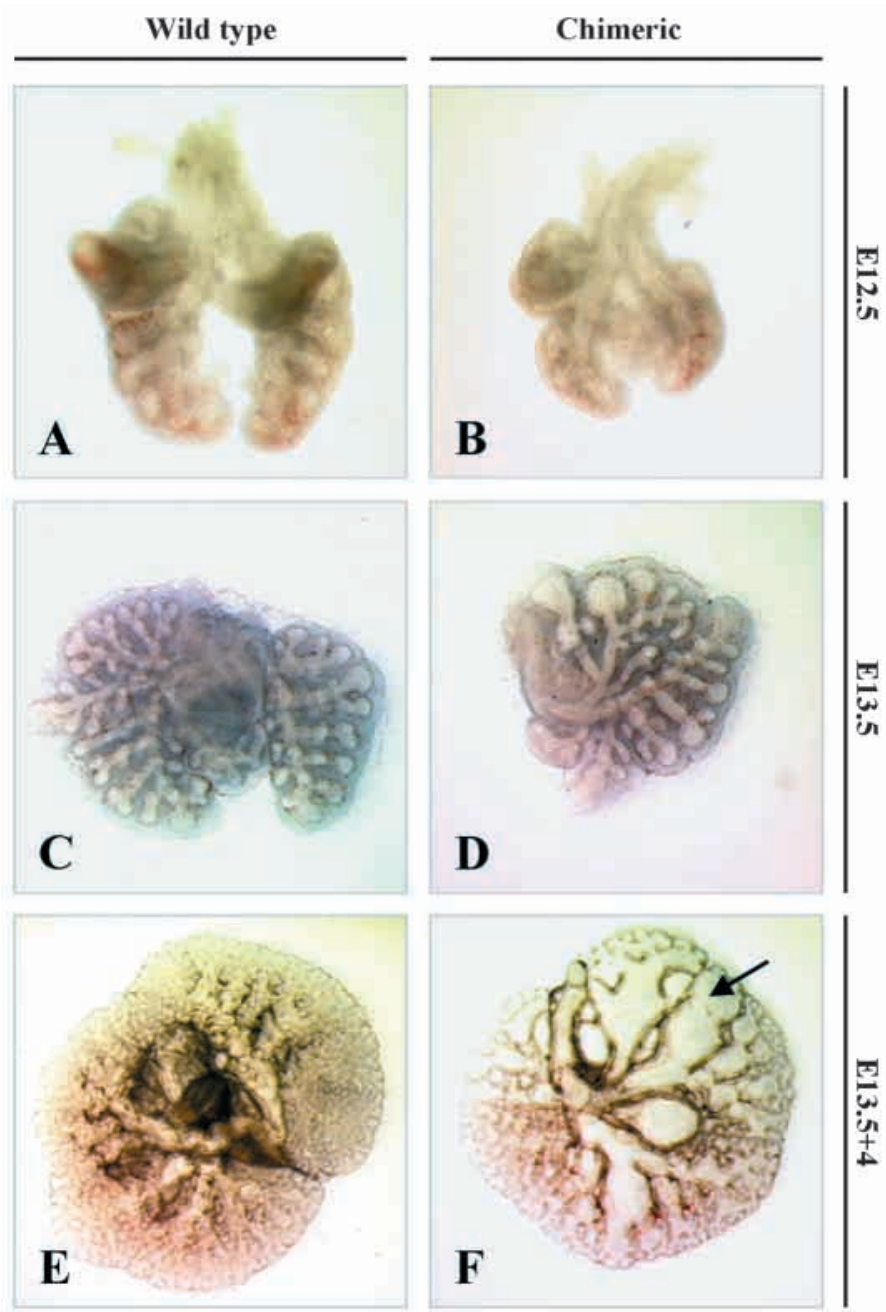

Fig. 3. Gata6 $6^{-1-}$ chimeric lungs display diminished branching morphogenesis in vitro. When isolated at E12.5, Gata $^{-1-}$ chimeric lungs (B) are smaller and have fewer branches than wild-type lungs isolated from a littermate (A). E13.5 wild-type (C) and Gata6 $^{-1-}$ chimeric (D) lungs at day 0 of culture as organotypic explants. After 4 days of culture (E,F), the ata6 $^{-1-}$ chimeric lungs had areas of normal and areas of diminished branching morphogenesis $(\mathrm{F})$, whereas in the wild type lung branching morphogenesis had occurred as normal (E). All pictures are representative of a series of experiments, and are at the same magnification. (Arrow indicates area with diminished branching morphogenesis.) 

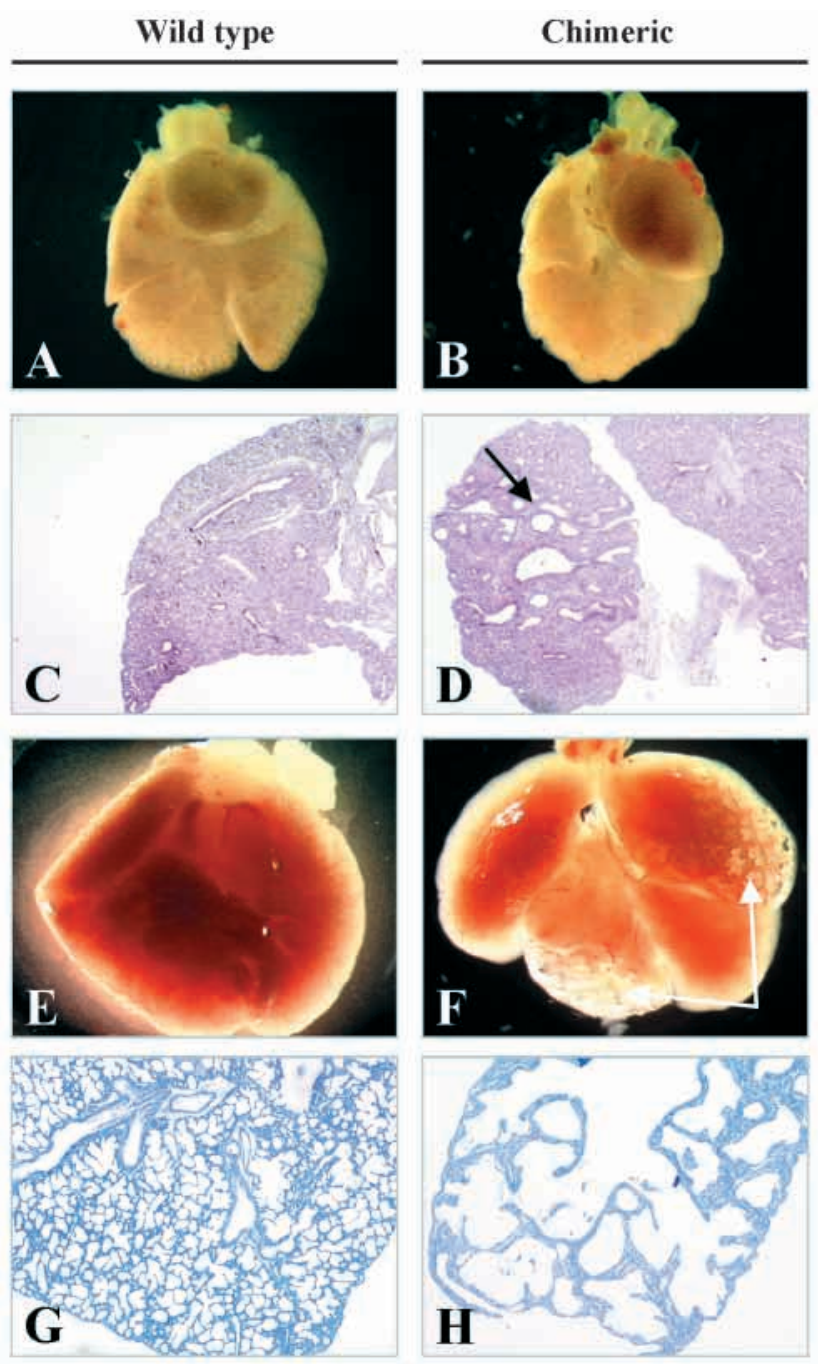

Fig. 4. Branching morphogenesis in vivo is diminished in $\mathrm{Gata6}^{-1-}$ chimeric lungs when compared with wild-type lungs. At E15.5 (AD), lungs appeared macroscopically indistinguishable when isolated from wild-type (A) or Gata6 $^{-1-}$ chimeric embryos (B). However, when microscopic sections were analyzed, Gata $^{-1-}$ chimeric lungs had bigger airspaces (D) that the lungs of wild-type embryos (C). At E18.5, Gata6 $^{-/-}$chimeric lungs $(\mathrm{F}, \mathrm{H})$ displayed diminished branching morphogenesis both macroscopically $(\mathrm{F})$ and microscopically $(\mathrm{H})$ when compared with lungs of wild-type littermates (E,G). All pictures are representative for a series of experiments and are at the same magnification. (Arrows indicate areas with diminished branching morphogenesis.)

differentiation, was performed. The promoters of the genes for both these proteins have previously been demonstrated to contain GATA motifs, indicating that the transcription of these genes may be regulated by GATA transcription factors (Ray et al., 1993; Wert et al., 1993). Another epithelial cell marker which has been shown to be regulated by GATA6 in vitro is TTF1. Localization of TTF1 protein was investigated in the Gata6 $^{-1-}$ chimeric lungs.

At E15.5 (Fig. 5A-C) and E18.5 (Fig. 5D-F), normal SPC expression was observed in Gata6 $^{-1-}$ chimeric lungs in the areas that appeared to have branched normally (Fig. 5B,C,E). In contrast, no SPC expression was observed in areas with abnormal big sacculi (Fig. 5B,C,F). Normal SPC expression was observed in the wild-type lungs in distal epithelium at E15.5 (Fig. 5A) and in type II cells at E18.5 (Fig. 5D).

At E15.5, no CC10 expression was observed in either wildtype or $\mathrm{Gata6}^{-/}$chimeric lungs, which was expected, because the gene for $\mathrm{CC} 10$ is not expressed at that stage (results not shown). At E18.5, CC10 was expressed in the proximal airways of wild-type lungs, as well as in the normally branched parts of the Gata6 $^{-1-}$ chimeric lungs (Fig. 5G,H). In the abnormally branched parts of the Gata $^{-/-}$chimeric lungs, no CC10 expression was observed (Fig. 5I).

At E15.5 and E18.5 TTF1 protein was localized normally in epithelial cells of both wild-type and $\mathrm{Gata6}^{-1-}$ chimeric lungs (Fig. 6A-F). No differences were observed between areas with normal or abnormal branching morphogenesis in the $\mathrm{Gata6}^{-/-}$ chimeric lungs.

\section{Contribution of Gata6 $^{-1-}$ ES cells in chimeric lungs}

In order to identify the origin of the endoderm of the abnormally branched areas, Gata6 $^{-1-}$ ES cells (white) were injected into ROSA26 blastocysts (blue). In the targeted ES cell clones we used for generation of the chimeras, Gata6 was inactivated by insertion of a lacZ marker gene (Koutsourakis et al., 1999). However, when we investigated $\beta$-galactosidase activity in early embryonic lungs, we could not detect activity in developing airways lined with pulmonary endoderm (results not shown). In contrast, $\beta$-galactosidase activity was detected in developing major vessels later during lung development (results not shown). Therefore, we did not expect any interference between $\beta$-galactosidase activity in ROSA26- and ES cell-derived endoderm.

Using this approach, a similar phenotype of E12.5 lungs was observed upon isolation as in the previous experiments. The Gata $^{-1-} \leftrightarrow$ ROSA26 chimeric lungs were smaller and had developed fewer lung buds (Fig. 7A). More interestingly, after detection of $\beta$-galactosidase activity, completely white endodermal buds as well as mixtures of white and blue endodermal cells and completely blue endodermal buds were observed in highly chimeric lungs (Fig. 7B). In E15.5 Gata $^{-1-} \leftrightarrow$ ROSA26 chimeric lungs, the same observations were made (Fig. 8A,B). Areas with reduced branching morphogenesis had almost completely white endoderm derived from Gata6 $^{-1-}$ ES cells (Fig. 8A,B, arrows), whereas areas with normal branching morphogenesis had completely blue endoderm, derived from the wild-type ROSA26 host blastocyst cells (Fig. 8A,B).

\section{DISCUSSION}

Based on experiments using chimeric embryos and extrapolation of results obtained in other organs and model systems, GATA6 was presumed to be essential for the specification of foregut endoderm into pulmonary endoderm (Kalb et al., 1998; Morrisey et al., 1998). Using experiments with antisense oligonucleotides in organotypic explant cultures, and (in particular) chimeric experiments with $\mathrm{Gata6}^{-1-}$ ES cells, we provide evidence for a different and more extensive role for GATA6 in fetal pulmonary development than the previously proposed role of endoderm specification. In lung explants with already specified lung 

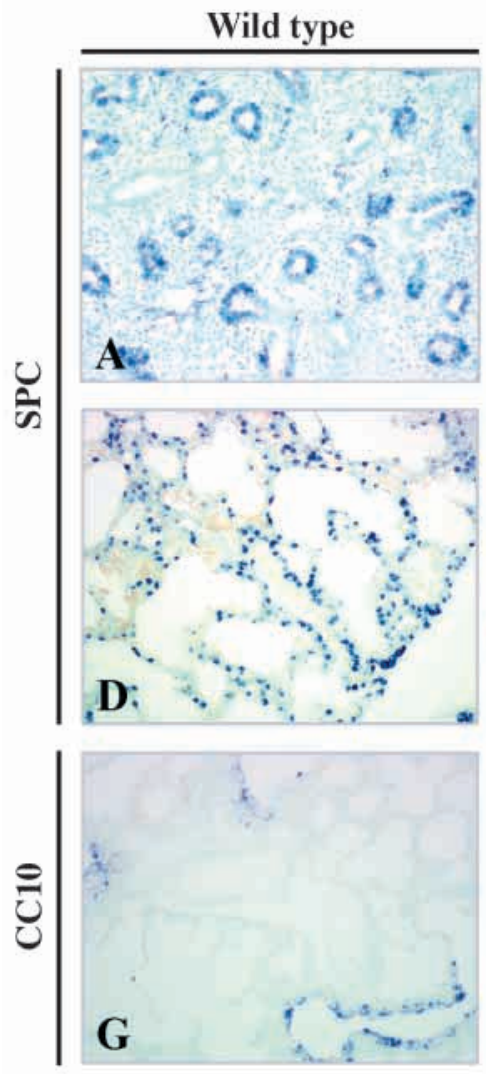

H
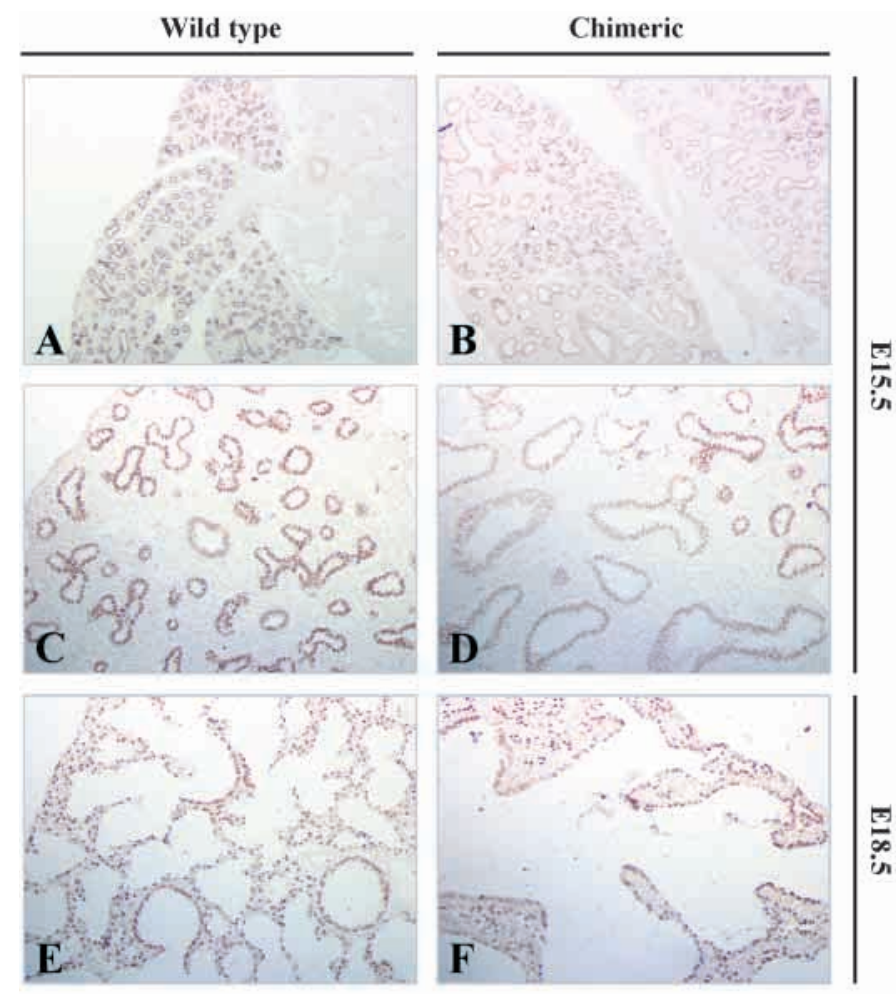

Fig. 6. Thyroid transcription factor 1 (TTF1) protein distribution as a marker for pulmonary endoderm specification. In wild-type (A,C,E) and Gata6 $^{-1-}$ chimeric (B,D,F) lungs, similar patterns of TTF1 protein distribution were observed at E15.5 (A-D) and E18.5 (E,F). (A,B) Low-power overview of E15.5. (C-F) Same magnification.

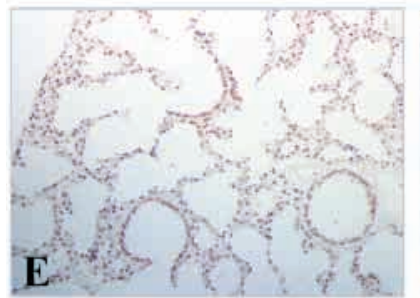

\section{Chimeric}
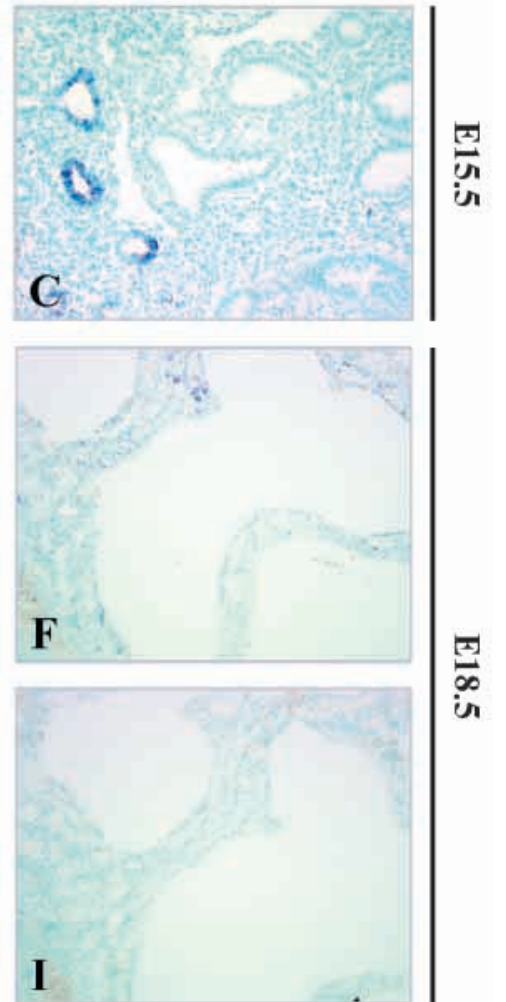

Fig. 5. mRNA distribution of molecular markers for distal (SPC) (A-F) and proximal (CC10) (G-I) epithelial cell differentiation. In both E15.5 (A-C) and E18.5 (D-F) embryos, SPC mRNA was expressed in normally branched areas of wild-type $(\mathrm{A}, \mathrm{D})$ and $\mathrm{Gata6}^{-1-}$ chimeric $(\mathrm{B}, \mathrm{E})$ lungs. No SPC mRNA expression was observed in abnormally branched areas of Gata6 $^{-1-}$ chimeric lungs (B,C,F). At E18.5, CC10 mRNA was expressed in normally branched areas of both wild-type $(\mathrm{G})$ and Gata6 $^{-1-}$ chimeric lungs $(\mathrm{H})$, whereas in abnormally branched areas of $\mathrm{Gata6}^{-/-}$ chimeric lungs, no $\mathrm{CC} 10$ mRNA expression could be observed. All pictures are at the same magnification, except $\mathrm{B}$, which is a lowpower overview of $\mathrm{C}$. endoderm (wild type) we could abrogate branching morphogenesis in vitro by culturing the explants in the presence of antisense oligonucleotides against Gata6. In agreement with this, highly chimeric lungs displayed diminished branching morphogenesis both in vitro and in vivo at different gestational ages. Proximal and distal epithelial cell differentiation was attenuated in chimeric lungs, as indicated by diminished expression of markers for distal and proximal epithelial cell differentiation, SPC and CC10 mRNA, respectively. TTF1, an early pulmonary epithelial cell marker that has also been shown to be regulated by GATA6 in vitro, was expressed as normal in chimeric lungs both at E15.5 and E18.5, indicating that endoderm specification occurred normally. In accordance with this, we found that Gata6 $^{-1-} \mathrm{ES}$ cells contribute to pulmonary endoderm in highly chimeric lungs, and, consequently, the observed phenotype of reduced branching morphogenesis and attenuated epithelial cell differentiation is the result of loss of function of GATA6 in pulmonary endoderm.

\section{GATA6 is essential for branching morphogenesis}

Using both in vitro and in vivo experiments, we demonstrate here that GATA6 plays an essential role during certain stages of branching morphogenesis in the lung. Specification of foregut endoderm into pulmonary endoderm occurred normally in the chimeric lungs, because we obtained highly chimeric embryos with lungs that had undergone morphogenesis. Outgrowth of two endodermally derived primary lung buds initiates the process of lung formation. Thus, highly chimeric lungs successfully completed the earliest phase of lung development, i.e. the specification of pulmonary 
endoderm. The next event in lung development, formation of four primary lung buds on the right and one primary lung bud on the left in mice, also occurred normally in highly chimeric lungs, since all isolated lungs at E12.5, E13.5, E15.5 and E18.5 had four lobes on the right and one lobe on the left side. This indicates that primary branching morphogenesis does not require GATA6. Consequently, the observed phenotype of reduced branching morphogenesis in lungs of highly chimeric embryos is the result of an essential role for GATA6 in secondary branching morphogenesis, the next stage of early pulmonary development. Either by blocking wild-type GATA6 translation with antisense oligonucleotides, or by depleting GATA6 function in chimeric lung endoderm, we demonstrate that absence of GATA6 gives rise to reduced branching morphogenesis. This resulted in lungs with very big airspaces. However, these lungs appeared no smaller than wild-type lungs, and when a marker for proliferation (Ki-67) was investigated in chimeric and wild-type lungs, no differences were observed (results not shown). Thus, the observed defect in branching morphogenesis is not the result of growth or proliferation inhibition by GATA6. For future studies it will be very interesting to investigate expression patterns of other molecules that have been demonstrated to play an important role during branching morphogenesis. Endodermally expressed markers like sonic hedgehog (SHH) (Litingtung et al., 1998), bone morphogenetic protein 4 (BMP4) (Bellusci et al., 1996) and hepatocyte nuclear factor/forkhead homolog 4 (HFH4; FOXJ1 - Mouse Genome Informatics) (Chen et al., 1998), as well as mesenchymally expressed markers like fibroblast growth factor 10 (FGF10) (Sekine et al., 1999) and GATA5 (Morrisey et al., 1997a) are likely candidates.

\section{GATA6 is essential for late epithelial cell differentiation, but not endoderm specification}

In highly chimeric lungs, we could not detect expression of SPC and CC10 mRNA in abnormally branched areas, indicating that both proximal and distal epithelial cell differentiation is disturbed in these parts of the lungs. In areas that had undergone normal branching morphogenesis SPC and CC10 were normally expressed. These data provide evidence for a functional role of the GATA motifs in the promoters of the genes for human SPC and murine CC10 in vivo (Ray et al., 1993; Wert et al., 1993). Another gene that is thought to be regulated by GATA6 on the basis of in vitro studies is TTF1 (ShawWhite et al., 1999). In addition, TTF1 alone has been demonstrated to regulate transcription of SPC and CC10 (Kelly et al., 1996; Zhang et al., 1997). Nevertheless, we could not detect any differences in protein expression of TTF1 between chimeric and wild-type lungs using immunohistochemistry with an antibody against TTF1. This indicates that downregulation of the expression of the late epithelial markers SPC and CC10 does not function through down-regulation of TTF1, which suggests that if GATA6 and TTF1 regulate SPC and CC10 gene transcription, they do it through different pathways. The fact that we observed normal expression of TTF1 protein, a marker for lung endoderm specification, indicates that specification of foregut endoderm into pulmonary endoderm occurred normally in the chimeric lungs. Hence, we conclude that GATA6 is not involved in pulmonary endoderm specification, as has been suggested before (Morrisey et al., 1998). This conclusion corroborates with recent data obtained in experiments with Xenopus in which both GATA4 and GATA5 were demonstrated to induce early endodermal marker genes, whereas GATA6 was demonstrated not to induce these endodermal markers (Weber et al., 2000).

\section{Gata6 $^{-/}$ES cells do contribute to pulmonary endoderm}

Using ROSA26 blastocysts (blue) as host blastocysts for Gata6 $^{-1-}$ ES cells (white), we were able to demonstrate contribution of Gata6 $^{-/-}$ES cells to pulmonary endoderm. Abnormally branched areas in E15.5 chimeric lungs had consistently white endoderm $\left(\mathrm{Gata6}^{-/}\right)$and normally branched areas blue endoderm (wild type) and therefore we

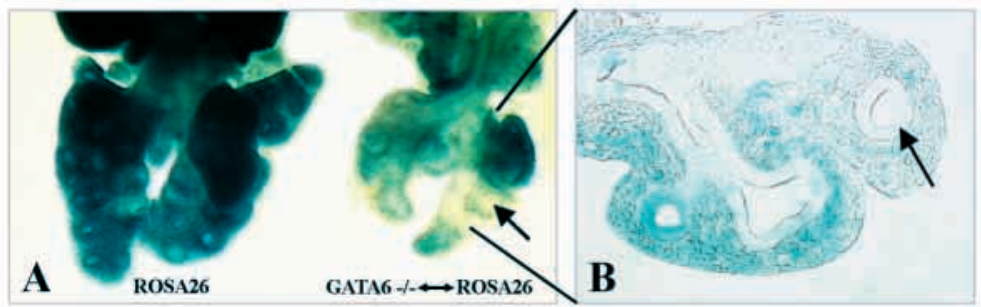

Fig. 7. Distribution of $\mathrm{Gata6}^{-1-}$ ES cell contribution into ROSA26 host lungs. (A) Gata6 $^{-1-}$ ES cells (white) contribute to both mesenchyme and endoderm of E12.5 chimeric lungs (right), which are smaller and have fewer branches than lungs from wild-type littermates (left). In a section of the chimeric lung (B), blue (wild-type ROSA26), mixed white and blue, and white $\left(\right.$ Gata6 $\left.^{-I_{-}}\right)$endoderm are observed, clearly indicating that $\mathrm{Gata6}^{-{ }^{-}}$ES cells do contribute to pulmonary endoderm (please note, as opposed to the usual experiment, that the white areas are abnormal and the blue areas normal). Arrows indicate white endoderm derived from Gata $^{-1-}$ ES cells.
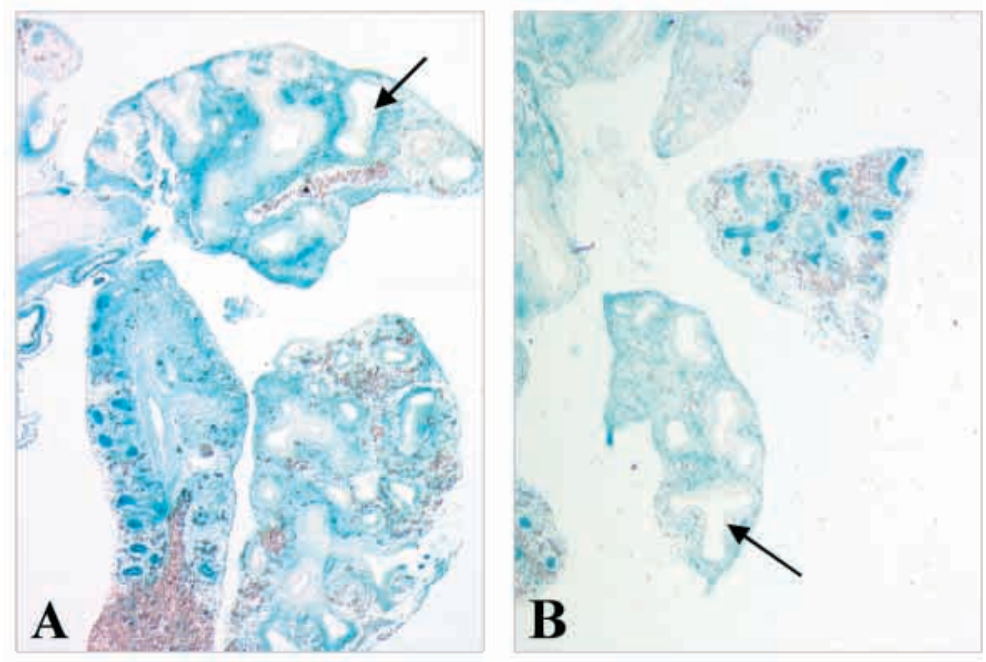

Fig. 8. Distribution of $\mathrm{Gata}^{-/-}$ES cell contribution in E15.5 lungs. Both sections of different $\mathrm{Gata6}^{-1-}$ chimeric lungs contain areas with abnormal branching morphogenesis that have white endoderm $\left(\right.$ Gata $\left.^{-l-}\right)$ and areas with normal branching morphogenesis which have blue endoderm coming from the wild-type ROSA 26 blastocyst. (Arrows indicate white endoderm derived from Gata6 $^{-1-}$ ES cells). 
conclude that reduced branching morphogenesis in $\mathrm{Gata6}^{-/-}$ chimeric lungs is the result of defective GATA6 mutant endoderm. Since we observed different areas with either blue, white or mixed white and blue endodermal cells and not lungs or lobes that were completely white or blue, it is likely that the lungs originate from a substantial number of cells from the foregut. Our observations are in contrast with data presented by another group, demonstrating that $\mathrm{Gata6}^{-1-}$ ES cells do not contribute to the bronchial epithelium in chimeric lungs, and concluded that GATA6 is required for establishment of the endodermally derived bronchial epithelium (Morrisey et al., 1998). The contradiction in observations can be explained by the different approach that we used in order to obtain animals that were highly chimeric. Whereas regular protocols suggest the injection of nine to $12 \mathrm{ES}$ cells into blastocysts to generate chimeric embryos (Hogan et al., 1994), we used double the number of ES cells to obtain highly chimeric embryos. GPI electrophoresis revealed that most chimeric embryos were derived from at least $50 \%$ Gata6 $^{-1-}$ ES cells and only chimeric embryos that were derived from more than $50 \%$ Gata6 $^{-1-}$ ES cells were used in our experiments. If we assume that selection by competition between wild-type and mutant cells occurs during the earliest stages of lung development in favor of wildtype cells, then the regular amount of $\mathrm{Gata6}^{-/-}$ES cells (as used by Morrisey et al.) may not have progeny in pulmonary endoderm. However, by using more $\mathrm{Gata}^{-1-}$ ES cells, mutant cells were able to survive competition and to contribute to pulmonary endoderm. To overcome any interference that resulted from the percentage of wild-type cells present during early pulmonary specification of these chimeric lungs, it will be of interest to generate embryos exclusively derived from Gata6 $^{-1-}$ ES cells. However, in all our experiments we never found embryos that were close to $100 \%$ chimeric (based on GPI electrophoresis), although a number of implantation sites with resorbed embryos were present. Based on the fact that GATA6 is not only expressed in extra-embryonic tissues, but also in embryonic tissues (Koutsourakis et al., 1999; Morrisey et al., 1996; Morrisey et al., 1998) it is likely that embryos exclusively derived from Gata6 $^{-1-}$ ES cells do not survive to later stages of gestation. Hence, it is unlikely that the use of methods such as the generation of tetraploid embryo chimeras would answer this question. It will probably require the generation of conditional knockout mice.

\section{Role for GATA6 in epithelial-mesenchymal interactions}

Since branching morphogenesis is highly dependent on epithelial-mesenchymal interactions (Hogan and Yingling, 1998), it is tempting to speculate which tissue layer causes the defect that reduces branching morphogenesis. Since the spatial-temporal distribution of Gata6 mRNA was predominantly observed in developing lung endoderm, it is most logical to postulate defective endoderm as the site where the primary defect is localized. Defective mutant Gata6 $^{-/-}$ endoderm appears unable to undergo normal branching morphogenesis and late epithelial cell differentiation resulting in the observed phenotype in the chimeric lungs. This would lead to the conclusion that the observed phenotype is based on a cell-autonomous defect in Gata6 $^{-1-}$ endodermal cells. However, there is an alternative explanation. Specification of pulmonary endoderm and primary branching morphogenesis occurs normally in a Gata6 $^{-/-}$environment, but at the initiation of subsequent branching morphogenesis, as yet unidentified signals produced by the endoderm are not processed normally by the mesenchyme, which in turn sends abnormal or no signals to the (up till that moment normal) endoderm. From then on, the endoderm would be instructed incorrectly by the mesenchyme, and would not undergo normal branching morphogenesis, resulting in big airspaces and attenuated epithelial cell differentiation. As a consequence, the observed phenotype is based on a cell-nonautonomous defect. Whichever scenario proves right, further investigation is warranted, and studies using transgenic and conditional knockout mice would be invaluable. Another important question not addressed in this study is what the early target genes for GATA6 in pulmonary development are. It is of interest whether known 'master' genes of branching morphogenesis such as Bmp4 (Bellusci et al., 1996), Shh (Litingtung et al., 1998) and members of the fibroblast growth factor family (Post et al., 1996; Sekine et al., 1999) are also transcriptionally regulated by GATA6. Future studies using immunoprecipitation, yeast two-hybrid screens and DNA microarray techniques, as well as detailed promoter analysis, should bring more insight.

\section{GATA6 function during pulmonary development: a hierarchical model}

Based on the results of our experiments, a reconsideration of the position of GATA6 in the hierarchy of factors involved in pulmonary development is warranted. To date Gata6 was considered to be one of the master genes in lung development (Whitsett and Tichelaar, 1999). Together with HNF3ß (Ang and Rossant, 1994) and TTF1 (Kimura et al., 1996), GATA6 was positioned high up in the hierarchy because all three factors were thought to be essential for the specification of foregut endoderm into pulmonary endoderm. However, in this study, we provide evidence that GATA6 is not essential for pulmonary endoderm specification, but plays an important role in branching morphogenesis and late epithelial cell differentiation. Therefore, we postulate that GATA6 functions (in concert with TTF1) in the process of branching morphogenesis and late epithelial cell differentiation.

We are grateful to Dr H. P. Roest for providing the ROSA26 mice. This work is supported by the Sophia Foundation for Medical Research, the David Vervat Foundation, NWO (NL) and the European Community.

\section{REFERENCES}

Ang, S. L. and Rossant, J. (1994). HNF-3 $\beta$ is essential for node and notochord formation in mouse development. Cell 78, 561-574.

Arceci, R. J., King, A. A., Simon, M. C., Orkin, S. H. and Wilson, D. B. (1993). Mouse GATA-4: a retinoic acid-inducible GATA-binding transcription factor expressed in endodermally derived tissues and heart. Mol. Cell. Biol. 13, 2235-2246.

Bellusci, S., Henderson, R., Winnier, G., Oikawa, T. and Hogan, B. L. (1996). Evidence from normal expression and targeted misexpression that bone morphogenetic protein (Bmp-4) plays a role in mouse embryonic lung morphogenesis. Development 122, 1693-1702.

Brewer, A., Gove, C., Davies, A., McNulty, C., Barrow, D., Koutsourakis, M., Farzaneh, F., Pizzey, J., Bomford, A. and Patient, R. (1999). The human and mouse GATA- 6 genes utilize two promoters and two initiation codons. J. Biol. Chem. 274, 38004-38016. 
Bruno, M. D., Korfhagen, T. R., Liu, C., Morrisey, E. E. and Whitsett, J. A. (2000). GATA-6 activates transcription of surfactant protein A. J. Biol. Chem. 275, 1043-1049.

Charron, F. and Nemer, M. (1999). GATA transcription factors and cardiac development. Semin. Cell Dev. Biol. 10, 85-91.

Chen, J., Knowles, H. J., Hebert, J. L. and Hackett, B. P. (1998). Mutation of the mouse hepatocyte nuclear factor/forkhead homologue 4 gene results in an absence of cilia and random left-right asymmetry. J. Clin. Invest. 102, 1077-1082.

Evans, T. (1997). Regulation of cardiac gene expression by GATA-4/5/6. Trends Cardiovasc. Med. 7, 75-83.

Friedrich, G. and Soriano, P. (1991). Promoter traps in embryonic stem cells: a genetic screen to identify and mutate developmental genes in mice. Genes Dev. 5, 1513-1523.

Hogan, B., Beddington, R., Constantini, F. and Lacy, E. (1994). Manipulating the Mouse Embryo. A Laboratory Manual. Cold Spring Harbor, NY: Cold Spring Harbor Laboratory Press.

Hogan, B. L. and Yingling, J. M. (1998). Epithelial/mesenchymal interactions and branching morphogenesis of the lung. Curr. Opin. Genet. Dev. 8, 481-486.

Hogan, B. L. (1999). Morphogenesis. Cell 96, 225-233.

Ikeda, K., Clark, J. C., Shaw-White, J. R., Stahlman, M. T., Boutell, C. J. and Whitsett, J. A. (1995). Gene structure and expression of human thyroid transcription factor-1 in respiratory epithelial cells. J. Biol. Chem. 270, 8108-8114.

Jordan, C. T. and Van Zant, G. (1998). Recent progress in identifying genes regulating hematopoietic stem cell function and fate. Curr. Opin. Cell Biol. 10, 716-720.

Kalb, J. M., Lau, K. K., Goszczynski, B., Fukushige, T., Moons, D., Okkema, P. G. and McGhee, J. D. (1998). pha-4 is Ce-fkh-1, a fork head/HNF-3alpha,beta,gamma homolog that functions in organogenesis of the C. elegans pharynx. Development 125, 2171-2180.

Keijzer, R., Liu, J., Deimling, J., Tibboel, D. and Post, M. (2000). Dual-hit hypothesis explains pulmonary hypoplasia in the nitrofen model of congenital diaphragmatic hernia. Am. J. Pathol. 156, 1299-1306.

Kelly, S. E., Bachurski, C. J., Burhans, M. S. and Glasser, S. W. (1996). Transcription of the lung-specific surfactant protein $C$ gene is mediated by thyroid transcription factor 1. J. Biol. Chem. 271, 6881-6888.

Kimura, S., Hara, Y., Pineau, T., Fernandez-Salguero, P., Fox, C. H., Ward, J. M. and Gonzalez, F. J. (1996). The T/ebp null mouse: thyroid-specific enhancer-binding protein is essential for the organogenesis of the thyroid, lung, ventral forebrain, and pituitary. Genes Dev. 10, 60-69.

Korfhagen, T. R., Bruno, M. D., Glasser, S. W., Ciraolo, P. J., Whitsett, J. A., Lattier, D. L., Wikenheiser, K. A. and Clark, J. C. (1992). Murine pulmonary surfactant SP-A gene: cloning, sequence, and transcriptional activity. Am. J. Physiol. 263, L546-L554.

Koutsourakis, M., Langeveld, A., Patient, R., Beddington, R. and Grosveld, F. (1999). The transcription factor GATA6 is essential for early extraembryonic development. Development 126, 723-732.

Laverriere, A. C., MacNeill, C., Mueller, C., Poelmann, R. E., Burch, J. B. and Evans, T. (1994). GATA-4/5/6, a subfamily of three transcription factors transcribed in developing heart and gut. J. Biol. Chem. 269, 2317723184.

Leonard, M., Brice, M., Engel, J. D. and Papayannopoulou, T. (1993). Dynamics of GATA transcription factor expression during erythroid differentiation. Blood 82, 1071-1079.

Litingtung, Y., Lei, L., Westphal, H. and Chiang, C. (1998). Sonic hedgehog is essential to foregut development. Nat. Genet. 20, 58-61.

Morrisey, E. E., Ip, H. S., Lu, M. M. and Parmacek, M. S. (1996). GATA6: a zinc finger transcription factor that is expressed in multiple cell lineages derived from lateral mesoderm. Dev. Biol. 177, 309-322.

Morrisey, E. E., Ip, H. S., Tang, Z., Lu, M. M. and Parmacek, M. S. (1997a). GATA-5: a transcriptional activator expressed in a novel temporally and spatially-restricted pattern during embryonic development. Dev. Biol. 183, 21-36.

Morrisey, E. E., Ip, H. S., Tang, Z. and Parmacek, M. S. (1997b). GATA-
4 activates transcription via two novel domains that are conserved within the GATA-4/5/6 subfamily. J. Biol. Chem. 272, 8515-8524.

Morrisey, E. E., Tang, Z., Sigrist, K., Lu, M. M., Jiang, F., Ip, H. S. and Parmacek, M. S. (1998). GATA6 regulates HNF4 and is required for differentiation of visceral endoderm in the mouse embryo. Genes Dev. 12, 3579-3590.

Motoyama, J., Liu, J., Mo, R., Ding, Q., Post, M. and Hui, C. C. (1998). Essential function of Gli2 and Gli3 in the formation of lung, trachea and oesophagus. Nat. Genet. 20, 54-57.

Orkin, S. H. (2000). Diversification of haematopoietic stem cells to specific lineages. Nat. Rev. Genet. 1, 57-64.

Pandolfi, P. P., Roth, M. E., Karis, A., Leonard, M. W., Dzierzak, E., Grosveld, F. G., Engel, J. D. and Lindenbaum, M. H. (1995). Targeted disruption of the GATA3 gene causes severe abnormalities in the nervous system and in fetal liver haematopoiesis. Nat. Genet. 11, 40-44.

Pevny, L., Simon, M. C., Robertson, E., Klein, W. H., Tsai, S. F., D'Agati, V., Orkin, S. H. and Costantini, F. (1991). Erythroid differentiation in chimaeric mice blocked by a targeted mutation in the gene for transcription factor GATA-1. Nature 349, 257-260.

Post, M., Souza, P., Liu, J., Tseu, I., Wang, J., Kuliszewski, M. and Tanswell, A. K. (1996). Keratinocyte growth factor and its receptor are involved in regulating early lung branching. Development 122, 3107-3115.

Ray, M. K., Magdaleno, S., O'Malley, B. W. and DeMayo, F. J. (1993). Cloning and characterization of the mouse Clara cell specific $10 \mathrm{kDa}$ protein gene: comparison of the $5^{\prime}$-flanking region with the human rat and rabbit gene. Biochem. Biophys. Res. Commun. 197, 163-171.

Sekine, K., Ohuchi, H., Fujiwara, M., Yamasaki, M., Yoshizawa, T., Sato, T., Yagishita, N., Matsui, D., Koga, Y., Itoh, N. et al. (1999). Fgf10 is essential for limb and lung formation. Nat. Genet. 21, 138-141.

Shaw-White, J. R., Bruno, M. D. and Whitsett, J. A. (1999). GATA-6 activates transcription of thyroid transcription factor-1. J. Biol. Chem. 274, 2658-2664.

Simon, M. C., Pevny, L., Wiles, M. V., Keller, G., Costantini, F. and Orkin, S. H. (1992). Rescue of erythroid development in gene targeted GATA-1mouse embryonic stem cells. Nat. Genet. 1, 92-98.

Ting, C. N., Olson, M. C., Barton, K. P. and Leiden, J. M. (1996). Transcription factor GATA-3 is required for development of the T-cell lineage. Nature 384, 474-478.

Tsai, F. Y., Keller, G., Kuo, F. C., Weiss, M., Chen, J., Rosenblatt, M., Alt, F. W. and Orkin, S. H. (1994). An early haematopoietic defect in mice lacking the transcription factor GATA-2. Nature 371, 221-226.

Warburton, D., Schwarz, M., Tefft, D., Flores-Delgado, G., Anderson, K. D. and Cardoso, W. V. (2000). The molecular basis of lung morphogenesis. Mech. Dev. 92, 55-81.

Weber, H., Symes, C. E., Walmsley, M. E., Rodaway, A. R. and Patient, R. K. (2000). A role for GATA5 in Xenopus endoderm specification. Development 127, 4345-4360.

Weiss, M. J., Keller, G. and Orkin, S. H. (1994). Novel insights into erythroid development revealed through in vitro differentiation of GATA-1 embryonic stem cells. Genes Dev. 8, 1184-1197.

Wert, S. E., Glasser, S. W., Korfhagen, T. R. and Whitsett, J. A. (1993). Transcriptional elements from the human SP-C gene direct expression in the primordial respiratory epithelium of transgenic mice. Dev. Biol. 156, 426443.

Whitsett, J. A. and Tichelaar, J. W. (1999). Forkhead transcription factor HFH-4 and respiratory epithelial cell differentiation. Am. J. Respir. Cell. Mol. Biol. 21, 153-154.

Whyatt, D., Lindeboom, F., Karis, A., Ferreira, R., Milot, E., Hendriks, R., de Bruijn, M., Langeveld, A., Gribnau, J., Grosveld, F. et al. (2000). An intrinsic but cell-nonautonomous defect in GATA-1-overexpressing mouse erythroid cells. Nature 406, 519-524.

Wilkinson, D. G. (1993). In situ hybridization. In Essential Developmental Biology. A Practical Approach, (ed. C. D. Stern and P. W. H. Holland), pp. 257-276. Oxford: IRL Press.

Zhang, L., Whitsett, J. A. and Stripp, B. R. (1997). Regulation of Clara cell secretory protein gene transcription by thyroid transcription factor-1. Biochim. Biophys. Acta 1350, 359-367. 